with a chisel and rongeur, an opening about two centimeters in diameter. The dura bulged and did not pulsate; it was opened with considerable escape of cerebrospinal fluid; distinct yellow lines of pus could be seen parallel with the vessels on the surface of the brain. The brain was probed downward, forward and backward to a depth of $3 \mathrm{~cm}$. and nothing found. A gauze drain was then placed inside the dura and pushed down towards the petrous portion of the temporal bone, the other end was brought out and through the external skin flap which was then sutured.

The patient made a rapid and uneventful recovery and was discharged from the hospital three weeks after the operation.

This is the second case of acute suppurative lepto-meningitis which I have seen recover; and I believe that many of these cases could be pulled through if operated on at once and a drain put into the subdural space. The cerebrospinal exudate along this drain will relieve the increased cerebrospinal pressure which is what kills most of the patients at once.

In clinics we often see cases that by sheer force of their own vitality survive the first stages of the disease and then pass into a chronic condition in which they may live for weeks. These are the cases that an early operation may pull through. In the case just described the mastoid was not opened at all for the reason that the infection seemed plainly via the roof of the tympanum and the patient was in such poor condition that I did not feel justified in adding to her shock by doing a mastoid operation in addition to the trephining. Her middle ear has since been treated by the ordinary method and is now nearly dry.

\section{GENERAL LYMPHO-SARCOMA ESPECIALLY ACTIVE IN THE THROAT.*}

\section{Preliminary Report.}

BY F. P. EMERSON, M.D., BOSTON.

April 30, 1901, Mr. W. was sent to me by Dr. P. and examination revealed the following condition: Patient, an American merchant, is forty-seven years of age, and was born in Boston. Denies venereal, tobacco or intemperance. Father died at seventy-five of cardiac disease, mother at seventy-four of carcinoma. One brother died of phthisis, one sister of scarlet fever, and one of typhoid fever. At eight years of age, Mr. W. had rheumatic fever which recurred annually for six or eight years. In 1898 he had an intestinal hemorrhage followed by fainting attacks. In 1899, fainting followed by vomiting of blood. In 1900 he developed hoarseness and experienced difficulty in talking distinctly. The nares are obstructed almost completely, apparently from collateral edema which does not contract under cocaine enough to give any view of the post-nasal space, or the turbinates. The uvula is club shaped and the size of a pecan. A ridge extends along the lateral walls of the pharynx which is smooth, of a cartilaginous feel and grayish color. Between these is a heaping up of tissue forming a rounded mass which interferes with deglutition. The eyelids are prominent and the conjunctivæ, especially at the outer third of the upper lids, forms a partial fold over the eyeball. The lower conjunctivæ are dotted with irregular

* Read at a meeting of the New England Otological and I aryngological Society, Nov. 17, 1905. rounded projections. The bridge of the nose is broadened. The face pale and, except for the intelligent look and quick mentality, one would almost think of myxedema. There is also cervical and inguinal adenitis, but no change could be detected in the spleen or liver. The heart shows moderate hypertrophy with a systolic murmur at the base and an intermittent pulse. His general appearance is that of a man sick with some wasting organic disease. His weight has dropped from 154 to 130 pounds, and he has been subject to so-called bilious attacks frequently, which are followed by clay-colored stools.

His appetite is poor and he has a sense of fullness at the epigastrium accompanied by muscular weakness and general depression. The temperature is normal, his pulse 80 and it intermits about one in seven beats. Diagnosis: A provisional diagnosis was made of syphilis and antileutic treatment commenced.

May 1, 1901. Examination of urine and sputum was negative. Blood: Hemoglobin $75 \%$. White cells 6,800 ; red, 3,568,000. Increase in lymphocytes negative. Microscopical examination: This was made at the pathological department of the Boston City Hospital and was from a snipping fromthe posterior pharyngeal wall. Gross: Spreading growth on the posterior wall of the pharynx, growing down on two sides in ridges as large as the little finger. Piece taken from the growing edge low down. Microscopical: A round cell growth very much resembling lymphoid tissue, showing very few mitotic figures and of evident slow formation. It has in the most part a definite capsule but in places is infiltrating the muscular tissue. The clinical history must be relied upon to determine its malignancy; a large definite tumor growth would suggest sarcoma.

Oct. 22, 1901. Mr. W. had gained two and one-half pounds when he had an attack of acute rheumatism, lasting two weeks. His weight is now $127 \frac{1}{2}$ pounds. During this attack his hoarseness, dysphagia and swelling of the lids improved but returned as the rheumatism grew better. Nov. 7, weight $132 \frac{1}{2}$ pounds; Nov. $15,133 \frac{1}{2}$ pounds, and Nov. 26, 134 pounds. Dec. 15, slight hemorrhage from the stomach and bowels. Jan. 23, hemorrhage; Feb. 15, 11 P.M., hemorrhage from the bowels, 12.45 and 1.45 from the stomach. The swelling of the eyes and throat diminished. Three days previous to these attacks he had yellow, watery dejections. No epigastric tenderness. The nares are now open, and he eats better, but is pale and weak. March 4, 1902. The pharynx is more swollen laterally and at the lower third. He chokes regularly on trying to eat. The lymphatirs in the neck, cheek and eyelids are more swollen. The eyelids at the outer third form a partial curtain over the eyeball. The uvula is two thirds its former size. His pulse intermits every seventh beat. Previous to this examination he had gained from 126 to 134 pounds. His uvula was decidedly smaller and I was loath to change his treatment, notwithstanding the microscopical examination, especially so, as his attack of acute rheumatism and four subsequent attacks of influenza had so interrupted my plans that it was difficult to draw definite conclusions in regard to it.

May 1, 1903. Mr. W. consulted a very careful and experienced observer who made a diagnosis of lupus and suggested arsenic. Beginning with one minim of Fowler's solution, this was increased to thirty, and the treatment extended over a period of one year. It was then omitted one year and resumed for two weeks, and again omitted. The first six months was interrupted by repeated acute infections, but at the end of the year, he was decidedly better. His throat was giving him little trouble, but he was thin and weak. 
Sept. 25, 1905. Examination: His eyelids are slightly swollen for which he again consults me, but patient says they have not been so for over a year until now. The bridge of the nose is somewhat broad. The nares are free and the uvula is normal. The pharynx is pale and the right lateral wall is a little swollen. No glands, pallor or muscular weakness. No spleen. No hemorrhage for four years. Appetite good. Weight, 154 pounds (normal). The blood shows no abnormal cells and is otherwise negative. Oct. 26 , patient has had a hemorrhage from the left nares which saturated two handkerchiefs, and the external swelling on the corresponding side of the nose has diminished, but not on the right.

\section{Ifportg of Sacietieg.}

\section{NEW ENGLAND OTOLOGICAL AND LARYNGOLOGICAL SOCIETY.}

Meeting Held at the Boston Medical Library, Nov. 17, 1905.

Philip Hammond, M.D., Secretary.

\section{DR. E. A. Crockett read a paper on}

SUCCESSFUL TREPHINING FOR ACUTE MENINGITIS, ${ }^{1}$

and Dr. Philip Hammond on

BRAIN ABSCESS. OPERATION, RECOVERY. ${ }^{2}$

DR. J. J. Putnam: I regret very much that I was not in time to hear I)r. Crockett's paper, but I misunderstood the time of the meeting. I judge that the case was one of great interest, because the operation for meningitis has seldom been successful. It certainly should be the dream of the surgeons to eventually learn how to treat the brain more or less with the same success as is obtained in diseases of the abdominal cavity.

With regard to Dr. Hammond's patient, whom I saw with him, I have very little to say, except that the case was a very obscure one as regards symptoms. When I examined him the question of abscess was discussed, but if I had not seen a very interesting case of cerebellar abscess a short time before, with Dr. Hammond, I do not know how strongly the idea would have been entertained..

It seems to me a very fortunate thing that both otologists and surgeons have shown the propriety of disregarding the sinus in taking off large pieces of the cranial bone. This is especially important with reference to operation on the cerebellum.

Abscesses in this region are extraordinarily silent and give rise to few symptoms, and the diagnosis must be, frequently, a matter of inference. If it is possible to attack the right half of the brain without danger of doing much harm, this is still more possible as regards the cerebellum.

In the case of a patient of mine, recently operated on by Dr. Mixter, a good part of the cerebellum was seriously damaged in the search for a tumor, without unpleasant results. Of course there is some danger that septic material may be carried inward, but this danger could, perhaps, be guarded against in most cases.

I think that every case of brain abscess should be studied with the greatest care, because we have had so very few successful ones in this neighborhood. Dr. Jack, I believe, has had one, but in the history of the Eye and Ear Infirmary the number of successfully

1 See p. 103.

2 See p. 102 . operated brain abscesses are very few. There are several reasons for this, and one of them is that it is sometimes difficult even when the abscess is struck, to know that it has been struck, because the pus is liable to be so thick and gummy that it will not flow through the trocar.

I should like to refer to one more patient. It has recently been shown that the subdural space, and even the brain, can be safely tapped in many places through minute openings in the skull without serious risk. Two writers, who have reported on this matter, refer to some eighty cases with about two hundred tappings, and assert that even etherization is not always necessary. This method should prove of great value in the differential diagnosis of meningitis.

Is it not true that advantage has been gained in the treatment of ear troubles by the removal of very large pieces of bone? I would also like to ask if the tendency has not been to make very much larger openings through the skull than were made formerly in both kinds of cases; and especially with meningitis cases, if not done very early, would there not be a great deal of benefit to the patient?

DR. Richards: Up to the present time I have had rather unfortunate experiences with my cases of brain abscess, all of them having died. Two of the cases are perhaps worthy of brief notice here in connection with Dr. Hammond's case and the remarks which Dr. Putnam has just made with reference to the obscurity of the cases and the difficulty of diagnosis.

The first case here mentioned I reported some years ago. The patient was a man in middle life who had gone to a general hospital for a slight pain in the head, accompanied with some ear discharge. After a few days' stay he was discharged at his own request, and on leaving the hospital in the afternoon, attempted to walk home, the distance being but a short one. As he did not reach home that evening, a search was made and he was found the next morning in a swamp, practically unconscious and was taken back to the same hospital at noon of the second day, totally unconscious and hemiplegic. Fxamination of the mastoid and tympanic cavity was negative. I then trephined with the usual round trephine through the squamous portion of the temporal directly above the tympanic cavity. The dura was dark in color, non-pulsating. It was incised, the opening extended about a quarter of an inch into the brain substance and about two ounces of extremely foul pus evacuated. The patient recovered partial consciousness but lived only three or four days. It is probable that this abscess had been in existence for some time without producing any symptoms, and the case illustrates the always potential danger of a case of old suppurative otitis media.

In the second case the cerebral symptoms suggested brain abscess and the tympanic cavity contained considerable polypoid degenerated material. The usual mastoid operation was done, small fistulous tract found leading directly into the brain, a large abscess found and evacuated. The difficulty here was one of drainage, and although I used rubber drainage tubes and metal drainage tubes, gauze wicking and everything I could think of in order to get the abscess drained and keep it drained, the discharge was so thick that it would not flow freely. I thought the patient would get well and he did live twelve days but finally died. It seemed as if the cause of death was improper drainage or insufficient drainage. An autopsy was not allowed but after death there was no difficulty in packing from two to three yards of one-inch gauze into the abscess cavity, and I think there was disintegration of very nearly the entire cortex of one hemisphere.

Occasionally a case gets well, while another does not, 